DOI: https://doi.org/10.24127/ajpm.v8i1.1891

\title{
KUALITAS PELAYANAN PENDIDIKAN DALAM MENGANALISIS KEPUASAN MAHASISWA PADA PROGRAM STUDI PENDIDIKAN MATEMATIKA
}

\author{
Atica Puspitaningtyas ${ }^{1}$, Ruhban Masykur ${ }^{2}$, Siska Andriani ${ }^{3}$ \\ 1,2,3 Pendidikan Matematika, UIN Raden Intan Lampung \\ E-mail: $\quad$ atica.puspita@gmail.com ${ }^{1)}$ \\ rmasykur@yahoo.co.id ${ }^{2)}$ \\ siskaandriani@radenintan.ac.id ${ }^{3)}$
}

Received 21 Februari 2019; Received in revised form 4 April 2019; Accepted 10 May 2019

\begin{abstract}
Service quality is an evaluation of the results of the process of comparing the services that consumers have received with the service they expect. Based on the results of observations that have been made found several student complaints about poor service quality, including in the form of facilities or infrastructure. The purpose of this study was to determine the level of student satisfaction with the quality of education services with the servqual method. This research is a descriptive qualitative study. The data analysis technique uses the servqual method and the importance performance analysis (IPA) method. The results in this study show that students are not satisfied with the educational services provided by the mathematics education department, whereas in the IPA analysis there are several service items which are included in the top priority namely timely attendance, security, friendliness, structuring the lecture room, AC facilities, LCD facilities and worship facilities.
\end{abstract}

Keywords: Importance Performance Analysis; Student Satisfaction; Servqual.

\section{PENDAHULUAN}

Lembaga pendidikan merupakan suatu lembaga yang memberikan pelayanan berupa pendidikan. Lembaga pendidikan diyakini mempunyai tugas yang sangat penting yaitu menyiapkan sumber daya manusia agar mampu bertindak sebagai pembawa perubahan dan pencerahan hidup lebih baik (Hidayati, Fudholi, \& Sumarni, 2014). Pendidikan menjadi salah satu modal penting untuk memajukan suatu bangsa karena kesejahteraan dan kemajuan sebuah bangsa dapat dilihat dari tingkat pendidikannya (Aini, Masykur, \& Komarudin, 2018). Oleh sebab itu kebutuhan masyarakat akan adanya pendidikan sangatlah meningkat terutama dalam pendidikan formal di perguruan tinggi. Pendidikan merupakan kebutuhan sepanjang hayat (Anggoro, 2016).
Sebagaimana faktanya tidak dapat dihindari banyaknya perguruan tinggi dengan program studi sejenis baik didalam maupun diluar negeri yang berstatus negeri maupun swasta mengakibatkan persaingan yang kompetitif antar lembaga pendidikan. Program studi pendidikan idealnya menghasilkan lulusan yang mampu bersaing dan menjawab tantangan zaman (Diana, 2017). Menurut Badan Akreditasi Nasional Perguruan Tinggi (BAN-PT), tuntutan yang diberikan masyarakat kepada perguruan tinggi meliputi jaminan kualitas (quality assurance), pengendalian kualitas (quality control), dan perbaikan kualitas (quality improvement) (Marlina, 2016). Berdasarkan hasil pra-penelitian diperoleh beberapan keluhan mahasiwa terhadap pelayanan yang telah dterimanya, seperti fasilitas toilet, faslitas LCD dan keramahan pelayanan 
dari OB program studi. Oleh karena itu, agar dapat memenuhi keinginan masyarakat tersebut program studi Pendidikan Matematika dituntut untuk mampu memberikan mutu pendidikan yang berkualitas dengan berupaya meningkatkan jasa atau layanan pendidikannya sehingga terciptanya kepuasan mahasiswa.

Kualitas berkaitan erat dengan kepuasan pelanggan. Kualitas memberikan dorongan khusus bagi para pelanggan untuk menjalin relasi saling menguntungkan dalam jangka panjang dengan perusahaan (Tjiptono \& Chandra, 2011). Mahasiswa merupakan bagian terpenting dari adanya perguruan tinggi, dalam penelitian ini kepuasan mahasiswa merupakan prioritas utama di program studi pendidikan matematika, untuk dapat menghasilkan pendidikan yang bermutu dan berkualitas perlu adanya evaluasi, karena evaluasi itu sendiri digunakan sebagai dasar pengambilan keputusan (Andriani, 2015).

Kotler mendefinisikan jasa sebagai setiap tindakan atau perbuatan yang dapat ditawarkan oleh suatu pihak kepada pihak lain yang pada dasarnya bersifat intangible (tidak berwujud fisik) dan tidak menghasilkan kepemilikan sesuatu (Tjiptono, 2014), walaupun demikian, produk jasa bisa berhubungan dengan produk fisik maupun tidak. Ditinjau dari sudut lembaga perguruan tinggi sebagai lembaga yang menawarkan jasa, maka perlu diketahui beberapa karakteristik penting yang terdapat di dalamnya meliputi (Adam, 2015): (1) Perguruan tinggi termasuk kedalam jasa murni, (2) Jasa yang diberikan membutuhkan kehadiran pengguna jasa (mahasiswa), (3) Penerima jasa adalah orang, jadi pemberi jasa yang berbasis orang, dan (4) Hubungan dengan pelanggan adalah berdasarkan member relationship, pelanggan telah menjadi anggota pendidikan tersebut.

Kualitas adalah seperangkat gambaran produk yang menimbulkan kepuasan pada pelanggan dan kualitas juga dapat memberikan nilai tambah produk atau dengan kata lain kualitas merupakan kemampuan sebuah produk atau jasa memuaskan kebutuhan atau tuntutan dari pelanggan. Pada penelitian awalnya, Parasuraman, et al mengidentifikasi sepuluh dimensi pokok kualitas jasa, namun pada riset selanjutnya menemukan adanya overlapping diantara beberapa dimensi tersebut, sehingga menyederhanakan sepuluh dimensi tersebut menjadi lima dimensi pokok, dengan demikian lima dimensi disusun sesuai urutan tingkat kepentingan relatifnya sebagai berikut: (Tjiptono \& Chandra, 2011)

1 Reliabilitas (Reliability) yaitu berkaitan dengan kemampuan perusahaan untuk memberikan layanan yang akurat sejak pertama kali tanpa membuat kesalahan apapun dan menyampaikan jasanya sesuai dangan waktu yang disepakati.

2 Daya tangkap (Responsiveness) yaitu berkenaan dengan kesedian dan kemampuan para karyawan untuk membantu para pelanggan dan merespon permintaan mereka, serta menginformasikan kapan jasa akan diberikan dan kemudian memberikan jasa secara cepat.

3 Jaminan (Assurance) yaitu perilaku para karyawan mampu menumbuhkan kepercayaan pelanggan terhadap perusahaan dan dapat menciptakan rasa aman bagi pelanggannya.

4 Empati (Empathy) yaitu perusahaan memahami masalah para pelanggannya dan bertindak demi kepentingan pelanggan, serta memberikan perhatian personal 
kepada para pelanggan dan memiliki jam operasi yang nyaman.

5 Bukti fisik (Tangibles) yaitu berkenaan dengan daya tarik fasilitas fisik, perlengkapan, dan material yang digunakan perusahaan, serta penampilan karyawan.

Kepuasan adalah perasaan senang atau kecewa yang timbul karena membandingkan kinerja yang dipersepsikan produk atau hasil terhadap ekspektasi mereka (Kotler \& Keller, 2009). Tingkat kepuasan pelanggan merupakan fungsi dari perbedaan antara kinerja yang dirasakan dengan harapan. Jika kinerja berada dibawah harapan, maka pelanggan menjadi kecewa, jika kenerja memenuhi harapan maka pelanggan menjadi puas, demikian juga halnya jika kinerja melebihi harapan pelanggan, maka pelanggan menjadi sangat puas atau senang (Hartono, 2017).

Penelitian ini sejalan dengan penelitian yang telah dilakukan oleh Haryadi Sarjono dan Natalia dengan judul penelitian Servqual Dalam Pelayanan Kelas pada Laboratorium Manajemen hasil pada penelitian tersebut diketahui bahwa tingkat kualitas layanan yang diberikan pada kelas laboraturium analisis kuantitatif bisnis kepada mahasiswa secara keseluruhan belum memuaskan, dengan hasil gap cukup besar pihak universitas perlu memberikan perhatian khusus pada dimensi yang memiliki gap tertinggi yaitu reliabilitas, tangible, dan responsiveness, namun tetap memperhatikan dimensi lainnya. Sejalan dengan penelitian tersebut, pada penelitian ini dilakukan pada program studi pendidikan matematika di salah satu universitas yang berada Lampung, dengan teknik penyebaran kuesioner secara online dan dengan bantuan sofeware SPSS 22.0 for windows.
Sehingga tujuan dalam penelitian ini adalah untuk mengetahui tingkat kepuasan mahasiswa terhadap kualitas pelayanan pendidikan dengan menggunakan metode servqual.

\section{METODE PENELITIAN}

Jenis penelitian yang dilakukan dalam penelitian ini merupakan jenis penelitian kulitatif yang bersifat deskriptif. Penelitian ini dilakukan kepada 90 mahasiswa program studi pendidikan matematika angkatan 20142017. Teknik sampling yang digunakan dalam penelitian ini menggunakan metode probability Sampling yaitu Proportionate Stratified Random Sampling, teknik ini digunakan bila populasi mempunyai mempunyai anggota atau unsur yang tidak homogen dan berstarta secara proporsional (Mahyudi, 2015). Penarikan sampel dilakukan dengan menggunakan rumus Slovin:

Keterangan:

$$
n=\frac{N}{1+N e^{2}}
$$

$$
\begin{array}{llr}
\mathrm{n} & =\text { Ukuran sampel } & \\
\mathrm{N} & =\text { Jumlah populasi } \\
\mathrm{e} & =\quad \text { Tingkat } & \text { kekeliruan } \\
& \text { pengambilan sampel yang dapat } \\
& \text { ditolerir }
\end{array}
$$

Populasi sebanyak 876 mahasiswa dengan taraf kesalahan 10\%, maka besarnya pengambilan sampel adalah 90 mahasiswa, penyebaran kuesioner dilakukan pada mahasiswa tahun angkatan 2014-2017 yang terpilih menjadi sampel penelitian.

Teknik pengumpulan data dilakukan dengan menggunakan teknik interview (wawancara) untuk mengemukakan permasalahan dalam melakukan studi pendahuluan, teknik observasi digunakan untuk memperoleh data secara terperinci dalam melihat 
kondisi dan keadaan secara langsung, teknik dokumentasi digunakan untuk memperoleh data jumlah mahasiswa yang diterima di program studi pendidikan matematika angkatan 20142017, dan kuesioner (angket) digunakan untuk memperoleh data tentang kepuasan mahasiswa terhadap kualitas pelayanan pendidikan.

Instrumen penelitian yang digunakan dalam penelitian ini adalah kuesioner berupa pernyataan tertulis yang harus dijawab oleh responden. Skala pengukuran yang digunakan sebagai alternatif jawaban dalam kuesioner ini adalah skala Likert dengan gradasi sangat tidak puas sampai sangat puas pada penilaian persepsi dan skala Likert dengan gradasi sangat tidak penting sampai sangat penting pada Tabel 1.

Tabel 1. Skor Pengukuran Pelayanan

\begin{tabular}{ccc}
\hline Persepsi & Harapan & Skor \\
\hline Sangat puas & Sangat penting & 5 \\
Puas & penting & 4 \\
Cukup puas & Cukup penting & 3 \\
Tidak puas & Tidak penting & 2 \\
Sangat tidak & Sangat tidak & 1 \\
puas & penting & \\
\hline
\end{tabular}

Uji coba intrumen dilakukan sebelum instrumen penelitian diberikan kepada responden yang termasuk kedalam sampel penelitian. Uji coba instrumen ini digunakan untuk melihat apakah setiap pernyataan yang akan diberikan nantinya valid dan reliabil atau tidak, namun sebelum melakukan uji coba penelitian, peneliti melakukan validasi terlebih dahulu untuk menentukan kelayakan angket yang akan diuji cobakan. Uji validitas dilakukan dengan menggunakan rumus koefesien korelasi Product Moment dengan taraf signifikan 5\%, sedangkan untuk uji reliabilitas dilakukan dengan menggunakan rumus koefesien Cronbach Alpha. Variabel penelitian yang digunakan terbagi kedalam lima dimensi kualitas jasa seperti Tabel 2.

Tabel 2. Variabel Penelitian

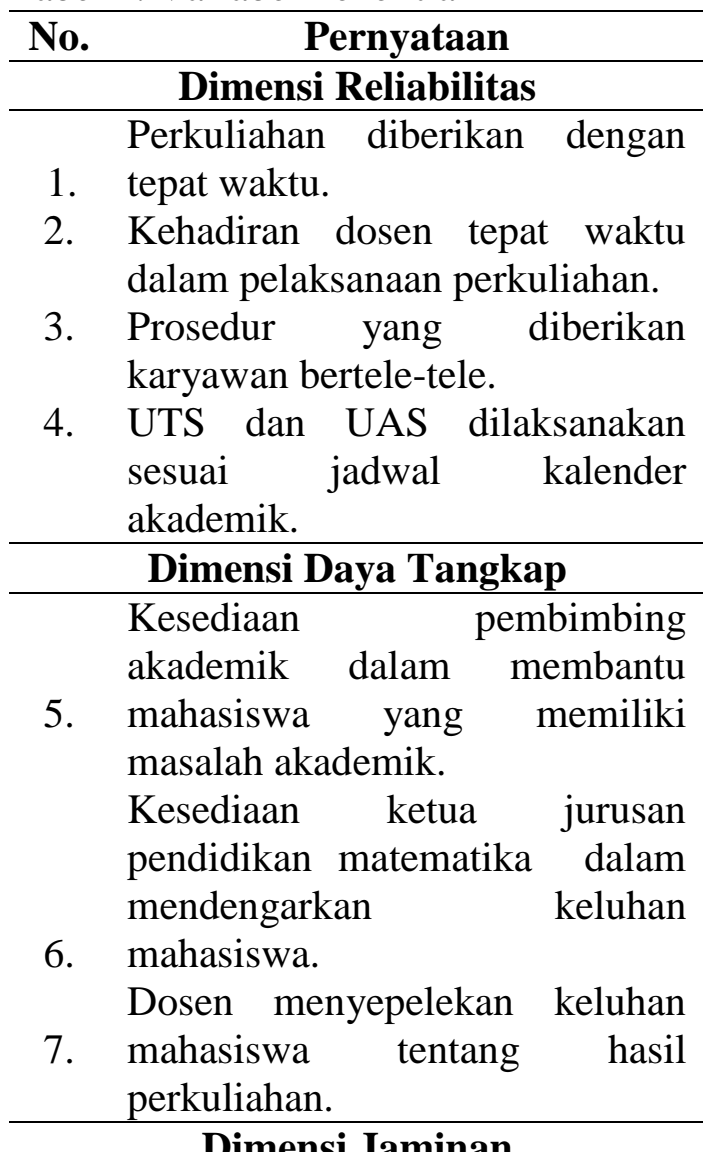

\section{Dimensi Jaminan}

Dosen memberikan tugas yang

8. sesuai dengan materi perkuliahan.

9. Dosen menyampaikan materi perkuliahan dengan jelas.

Dosen merendahkan mahasiswa

10. yang belum menguasai materi perkuliahan.

Dosen menyampaikan informasi

11. dengan bahasa yang baik dan sopan.

Tersedianya jaminan keamanan

12. di lingkungan jurusan pendidikan matematika.

\section{Dimensi Empati}

13. Ketua jurusan ramah dalam mendengarkan keluhan 
mahasiswa.

Dosen memberitahu mahasiswa

14. apabila ada pergantian hari pada perkuliahan.

15. Dosen mampu memberikan motivasi.

16. Kemudahan dalam menghubungi dosen.

17. Pelayanan yang ramah dari $\mathrm{OB}$ jurusan pendidikan matematika.

18. Penataan ruang kuliah yang nyaman.

\begin{tabular}{ll}
\multicolumn{3}{c}{ Dimensi Bukti Fisik } \\
\hline 19. & $\begin{array}{l}\text { Kesulitan dalam mendapatkan } \\
\text { informasi yang selalu update. } \\
\text { Website jurusan memberikan }\end{array}$ \\
20. & $\begin{array}{l}\text { informasi yang lengkap tentang } \\
\text { jurusan pendidikan matematika. }\end{array}$ \\
21. & $\begin{array}{l}\text { Kenyamanan fasilitas AC } \\
\text { disetiap ruang perkuliahan. }\end{array}$ \\
22. & Fasilitas toilet. \\
23. & $\begin{array}{l}\text { Perlunya media pembelajaran } \\
\text { berupa LCD. } \\
\text { Tempat ibadah yang nyaman dan } \\
\text { bersih. }\end{array}$ \\
\end{tabular}

Setelah melakukan penyebaran instrumen penelitian, hasil pada instrumen ini akan dianalisis menggunakan metode SERVQUAL dan Importance Performance Analysis.

\section{Analisis SERVQUAL}

Metode ini dikembangkan pada tahun 1985 oleh A. Parasuraman, Valarie A. Zeithaml, dan Leonard L. Berry lewat artikel mereka di journal of Marketing. Metode dijurnal tersebut lalu direvisi oleh mereka lewat artikel "SERVQUAL: "A Multiple-Item Scale for Measuring Perceptions of Service Quality" (Windasuri \& Susanti, 2017). Analisis kualitas pelayanan atau service quality (SERVQUAL) adalah metode deskriptif guna menggambarkan tingkat kepuasan pelanggan. Model ini didasarkan pada asumsi bahwa konsumen membandingkan kinerja jasa pada atribut-atribut relevan dengan standar ideal/sempurna untuk masingmasing atribut jasa. Bila kinerja sesuai dengan atau melebihi standar, maka persepsi atas kualitas jasa keseluruhan akan positif dan sebaliknya, model ini menganalisis gap anatara dua variabel pokok, yakni jasa yang diharapkan dan jasa yang dipersepsikan. Evaluasi kualitas jasa menggunakan model SERVQUAL mencakup perhitungan perbedaan diantara nilai yang diberikan pelanggan untuk setiap pasang pertanyaan berkaitan dengan harapan dan persepsi. Skor SERVQUAL untuk setiap pasang pertanyaan dapat dihitung dengan rumus:

Skor SERVQUAL = Skor Persepsi - Skor Harapan

\section{Importance Performance Analysis} Importance-Performance

Analysis (IPA) adalah sebuah teknik analisis deskriptif yang diperkenalkan oleh john A. Martilla dan John C. James pada tahun 1997. ImportancePerformance Analysis adalah suatu teknik analisis yang digunakan untuk mengidentifikasi faktor-faktor kinerja penting apa yang harus ditunjukan oleh suatu organisasi dalam memenuhi kepuasan para pengguna jasa (konsumen) (Suhendra \& Prasetyanto, 2016).

Pada metode ini menghasilkan diagram kertesius yang terbagi menjadi empat kuadran dan digunakan untuk menunjukan hubungan antara nilai kepentingan dan kinerja perusahaan dari item-item yang telah dinilai oleh responden dan untuk menentukan skala prioritas peningkatan layanan dalam rangka perbaikan kualitas pelayanan. Pembuatan diagram kartesius ini dilakukan dengan bantuan program aplikasi statistik yaitu software SPSS 22.0 for windows. Dalam metode ini terdapat beberapa tahapan dalam 
pembuatan digram kartesius yaitu: (Anggraeni, Deoranto, \& Ikasari, 2015)

Tahap pertama adalah menentukan tingkat kesesuaian antara tingkat kepentingan dan tingkat kinerja kualitas item yang ingin diteliti.

Keterangan:

$$
T k_{i}=\frac{X_{i}}{Y_{i}} \times 100 \%
$$

$T k_{i} \quad=$ Tingkat kesesuaian

$X_{i} \quad=$ Skor penilaian kinerja

$Y_{i} \quad=$ Skor penilaian kepentingan

Tahap kedua adalah menghitung rata-rata untuk setiap atribut yang dipersepsikan oleh konsumen, dengan rumus:

Keterangan:

$$
\bar{X}=\frac{\sum X_{i}}{n} \quad \bar{Y}=\frac{\sum Y_{i}}{n}
$$

$\bar{X} \quad=$ Skor rata-rata tingkat kinerja produk

$\bar{Y}=$ Skor rata-rata tingkat kepentingan terhadap produk

$\mathrm{N}=$ Jumlah responden

Selanjutnya dihitung rata-rata seluruh atribut tingkat kepentingan $(\overline{\bar{Y}})$ dan kinerja $(\overline{\bar{X}})$ yang menjadi batas pada diagram kartesius, dengan rumus:

$$
\overline{\bar{X}}=\frac{\sum \bar{X}_{l}}{k} \quad \overline{\bar{Y}}=\frac{\sum \bar{Y}_{l}}{k}
$$

Keterangan:

$\overline{\bar{X}} \quad=$ Rata-rata skor tingkat kineja produk seluruh faktor atau atribut

$\overline{\bar{Y}} \quad=$ Rata-rata tingkat kepentingan seluruh atribut yang mempengaruhi kepuasan konsumen

$\mathrm{K}$ = Banyaknya atribut yang dapat mempengaruhi kepuasan konsumen

Tahapan terakhir yaitu menjabarkan tiap atribut dalam diagram kartesius. Pada analisis kartesius tersebut nantinya akan didapat hasil berupa empat kuadran sesuai Gambar 1 .

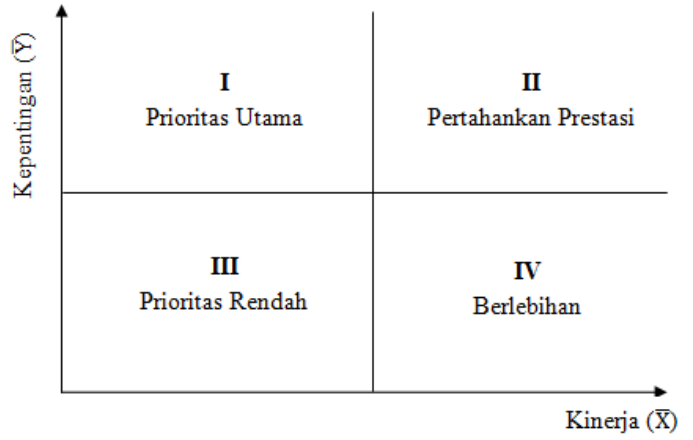

Gambar 1. Kuadran Importance Performance Analysis

Adapun interpretasi dari kuadran tersebut adalah sebagai berikut:

1 Prioritas utama menunjukan terdapat faktor-faktor yang dianggap penting atau diharapkan konsumen akan tetapi kinerja perusahaan dinilai belum memuaskan.

2 Pertahankan prestasi menunjukan terdapat faktor-faktor yang dianggap penting dan diharapkan sebagai faktor penunjang kepuasan konsumen.

3 Prioritas rendah menunjukan terdapat faktor-faktor yang dianggap mempunyai tingkat persepsi atau kinerja aktual yang rendah dan tidak terlalu penting atau tidak terlalu diharapkan oleh konsumen.

4 Berlebihan menunjukan terdapat faktor-faktor yang dianggap tidak terlalu penting dan tidak terlalu diharapkan oleh pelanggan.

\section{HASIL PENELITIAN DAN PEMBAHASAN}

Berdasarkan hasil uji validitas dan uji reliabilitas terhadap 30 pernyataan yang termasuk dalam data persepsi dan harapan yang telah diuji cobakan, diperoleh 24 pernyataan dengan kriteria valid pada data persepsi, dan 26 pernyataan dengan kriteria valid pada data harapan. Pada pengujian reliabilitas 
diperoleh nilai cronbach alpha pada data persepsi sebesar 0,8052 sedangkan pada data harapan diperoleh nilai cronbach alpha sebesar 0,8575, hal ini berarti $\mathrm{r}_{\text {hitung }}>0,367$, sehingga instrumen yang dinyatakan layak digunakan adalah 24 pernyataan.

Data yang digunakan dalam penelitian ini merupakan data primer pada kuesioner yang telah disebarkan kepada 90 mahasiswa pada Tabel 3.

Tabel 3. Karakteristik Responden

\begin{tabular}{lcc}
\hline \multicolumn{1}{c}{ Karakteristik } & Jumlah & Persentase \\
\hline Tahun Angkatan & & \\
$2014 / 2015$ & 24 & $27 \%$ \\
$2015 / 2016$ & 19 & $21 \%$ \\
$2016 / 2017$ & 25 & $28 \%$ \\
$2017 / 2018$ & 22 & $24 \%$ \\
Jenis Kelamin & & \\
Perempuan & 74 & $82 \%$ \\
Laki-laki & 16 & $18 \%$ \\
\hline
\end{tabular}

Berdasarkan hasil perhitungan skor servqual dari kuesioner yang telah diperoleh terhadap kualitas pelayanan pendidikan yang telah diberikan. Nilai rata-rata masing-masing item pernyataan dapat dilihat pada Tabel 4 .

Tabel 4. Skor Servqual Keseluruhan

\begin{tabular}{crrr}
\hline $\begin{array}{c}\text { Item } \\
\text { Pernya- } \\
\text { taan }\end{array}$ & $\begin{array}{c}\text { Rata- } \\
\text { rata } \\
\text { Persepsi }\end{array}$ & $\begin{array}{c}\text { Rata- } \\
\text { rata } \\
\text { Harapan }\end{array}$ & \multicolumn{1}{c}{ Gap } \\
\hline Item 1 & 3,567 & 4,222 & $-0,655$ \\
Item 2 & 3,333 & 4,178 & $-0,845$ \\
Item 3 & 3,356 & 2,356 & 1 \\
Item 4 & 3,767 & 4,011 & $-0,244$ \\
Item 5 & 3,411 & 4,322 & $-0,911$ \\
Item 6 & 3,6 & 4,278 & $-0,678$ \\
Item 7 & 3,378 & 2,678 & 0,7 \\
Item 8 & 3,822 & 4,044 & $-0,222$ \\
Item 9 & 3,6 & 4,2 & $-0,6$ \\
Item 10 & 3,667 & 3,022 & 0,645
\end{tabular}

\begin{tabular}{crrr} 
Item 11 & 3,856 & 4,156 & $-0,3$ \\
Item 12 & 3,244 & 4,344 & $-1,1$ \\
Item 13 & 3,7 & 4,178 & $-0,478$ \\
Item 14 & 3,711 & 4,133 & $-0,422$ \\
Item 15 & 3,667 & 4,056 & $-0,389$ \\
Item 16 & 3,389 & 4,178 & $-0,789$ \\
Item 17 & 2,167 & 4 & $-1,833$ \\
Item 18 & 3,367 & 4,178 & $-0,811$ \\
Item 19 & 2,878 & 2,067 & 0,811 \\
Item 20 & 3,567 & 4,233 & $-0,666$ \\
Item 21 & 2,6 & 4,278 & $-1,678$ \\
Item 22 & 3,767 & 1,888 & 1,879 \\
Item 23 & 2,333 & 4,5 & $-2,167$ \\
Item 24 & 2,756 & 4,444 & $-1,688$ \\
Total & 80,503 & 91,944 & $-11,441$ \\
\hline
\end{tabular}

Dari Tabel 4, diperoleh tiga urutan nilai gap negatif tertinggi yaitu pada item 23 diperoleh nilai gap sebesar -2,167, pada item 17 diperoleh nilai gap sebesar -1,833, dan pada item 24 diperoleh nilai gap sebesar $-1,688$. Nilai gap terkecil inilah menandakan bahwa mahasiswa sangat tidak puas, dan pada perhitungan tunggal servqual skor keseluruhan yang diperoleh yaitu 11,441. Setelah diperoleh skor servqual pada masing-masing item pernyataan yang merupakan hasil kesenjangan antara persepsi dan harapan selanjutnya yaitu skor servqual pada masing-masing dimensi kualitas pelayanan jasa.

Tabel 5. Skor Servqual Per Dimensi

\begin{tabular}{lrrr}
\hline \multicolumn{1}{c}{ Dimensi } & Persepsi & Harapan & Gap \\
\hline Reliabilitas & 14,023 & 14,767 & 0,744 \\
$\begin{array}{l}\text { Daya } \\
\text { tangkap }\end{array}$ & 10,389 & 11,278 & 0,889 \\
Jaminan & 18,189 & 19,766 & 1,577 \\
& & & - \\
Empati & 16,634 & 20,545 & 3,911 \\
Bukti Fisik & 21,268 & 25,588 & $-4,32$ \\
\hline
\end{tabular}


Berdasarkan Tabel 5 diperoleh bahwa dimensi bukti fisik yang bekenaan dengan fasilitas fisik, perlengkapan dan meteril memiliki nilai gap terbesar diantara dimensi lainnya. pada dimensi reliabilitas diperoleh nilai gap sebesar $-0,744$, pada dimensi daya tangkap diperoleh nilai gap sebesar 0,889, pada dimensi jaminan diperoleh nilai gap sebesar -1,577, pada dimensi empati diperoleh nilai gap sebesar 3,911, dan pada dimensi bukti fisik diperoleh nilai gap sebesar -4,32.

Analisis selanjutnya yaitu dengan metode Importance Performance Analysis (IPA), metode ini dilakukan dengan memetakan tingkat harapan mahasiswa kedalam sumbu $\mathrm{Y}$ dan tingkat kepentingan atau persepsi mahasiswa kedalam sumbu $\mathrm{X}$ dengan kuadran-kuadran yang telah dikategorikan dalam pembuatan diagram kartesius, pemetaan tersebut terdiri dari setiap item pernyataan dan dimensi dari pelayanan program studi seperti Gambar 2.

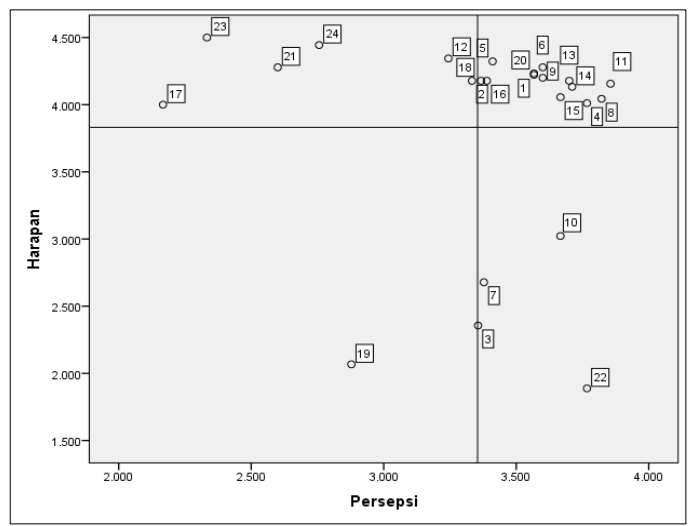

Gambar 2. Diagram Kartesius Persepsi dan Harapan Berdasarkan Item Layanan

Setelah dilakukan pengolahan data menggunakan batuan software SPSS 22.0 for windows, maka dapat ditentukan letak item-item pelayanan yang termasuk kedalam kuadran I, II, III, dan IV. Pada kuadran 1 terdapat 6 layanan yang termasuk dalam kategori prioritas utama, pada kuadaran II terdapat 13 layanan yang termasuk dalam kategori pertahankan prestasi, pada kuadran III terdapat 1 layanan yang termasuk dalam kategori prioritas rendah, dan terdapat 4 layanan yang termasuk dalam kategori berlebihan.

Analisis berikutnya dilakukan dengan perhitungan yang sama terhadap masing-masing variabel dimensi layanan yang terdiri dari dimensi reliabilitas, dimensi daya tangkap, dimensi jaminan, dimensi empati dan dimensi bukti fisik.

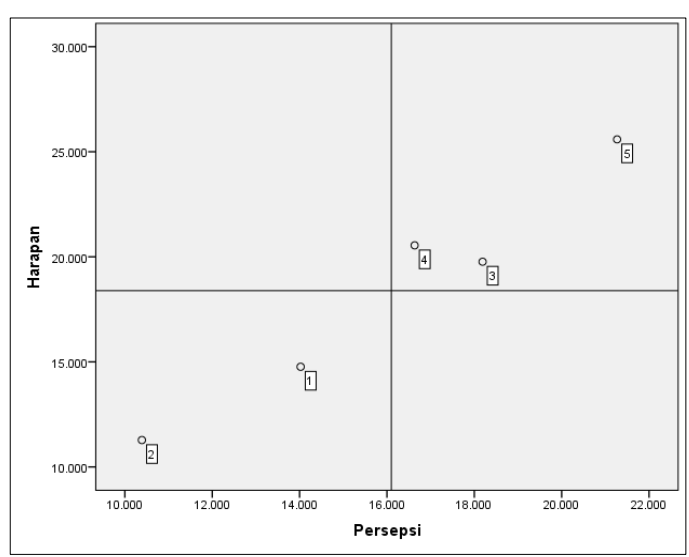

Gambar 3. Diagram Kartesius Persepsi dan Harapan Berdasarkan Dimensi Layanan

Berdasarkan Gambar 3 diagram kartesius yang terbagi menjadi 4 kuadran, menunjukan bahwa pada kuadran II terdapat 3 dimensi yang termasuk dalam kategori pertahankan prestasi dan pada kuadran III terdapat 2 dimensi yang termasuk dalam kategori prioritas rendah. Berikut Tabel 6 yang disajikan untuk memudahkan dalam memahami dan membaca diagram kartesius. 
DOI: https://doi.org/10.24127/ajpm.v8i1.1891

Tabel 6. Jumlah Item dan Dimensi Pelayanan Pada MasingMasing Kategori

\begin{tabular}{|c|c|c|c|c|c|}
\hline $\begin{array}{l}\text { Kua- } \\
\text { dran }\end{array}$ & Kategori & $\begin{array}{c}\text { Nomor } \\
\text { item } \\
\text { pelayanan }\end{array}$ & Jumlah & $\begin{array}{l}\text { Nomor } \\
\text { dimensi } \\
\text { layanan }\end{array}$ & Jumlah \\
\hline I & $\begin{array}{c}\text { Prioritas } \\
\text { utama }\end{array}$ & $\begin{array}{l}2,12,17 \\
21,23,24\end{array}$ & 6 item & 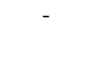 & 0 item \\
\hline II & $\begin{array}{c}\text { Pertahankan } \\
\text { prestasi }\end{array}$ & $\begin{array}{c}1,4,5,6 \\
8,9,11 \\
13,14 \\
15,16 \\
18,20\end{array}$ & $\begin{array}{c}13 \\
\text { item }\end{array}$ & $3,4,5$ & 3 item \\
\hline III & $\begin{array}{c}\text { Prioritas } \\
\text { rendah }\end{array}$ & 19 & 1 item & 1,2 & 2 item \\
\hline IV & Berlebihan & $\begin{array}{c}3,7,10 \\
22\end{array}$ & 4 item & - & 0 item \\
\hline
\end{tabular}

Berdasarkan Tabel 6 tersebut yang termasuk dalam kuadran I atau prioritas utama dengan persepsi rendah dan harapan tinggi menunjukan bahwa terdapat 6 item pelayanan yang perlu diprioritaskan karena dianggap penting dan diharapkan mahasiswa namun kinerja pelaksanaannya belum memuaskan, sehingga pihak jurusan lebih memperhatikan dan meningkatkan item pelayanan yang termasuk dalam kuadran ini. Pada kuadran II atau pertahankan prestasi dengan persepsi tinggi dan harapan tinggi menunjukan bahwa terdapat 13 item pelayanan dan 3 dimensi yang perlu dipertahankan karena tingkat kinerja yang diberikan oleh pihak jurusan dianggap sudah sesuai dengan harapan mahasiswa, sehingga dapat memuaskan mahasiswa. Pada kuadran III atau prioritas rendah dengan persepsi rendah dan harapan rendah menunjukan bahwa terdapat 1 item pelayanan dan 2 dimensi pelayanan yang dianggap kinerjanya cukup dan tidak terlalu diharapkan oleh mahasiswa, oleh karena itu pihak jurusan anggap tidak perlu memprioritaskan item pelayanan ini yang masuk dalam kuadran ini. Sedangkan pada kuadran IV atau berlebihan dengan persepsi tinggi dan harapan rendah menunjukan terdapat 4 item pelayanan yang dianggap kinerjanya sangat baik namun mahasiswa tidak terlalu mengharapkan, sehingga 4 item pelayanan ini dianggap sangat memuaskan mahasiswa.

\section{KESIMPULAN DAN SARAN}

Berdasarkan hasil penelitian dan pembahasan yang telah dilakukan dari hasil evaluasi kualitas pelayanan pendidikan di program studi pendidikan matematika dapat disimpulkan bahwa mahasiswa tidak puas terhadap pelayanan yang telah diberikan, hal ini didasarkan pada pengukuran gap analysis antara persepsi dan harapan yang diperoleh hasil gap negatif, dalam hal ini berarti mahasiswa belum menerima layanan pendidikan yang sesuai dengan harapannya. Tidak terpenuhinya kebutuhan dan kepuasan mahasiswa ini ditunjukan oleh beberapa item yang termasuk kedalam kuadran I atau prioritas rendah pada diagram kartesius, yaitu kehadiran dosen tepat waktu, jaminan keamanan di lingkungan jurusan pendidikan matematika, keramahan OB jurusan, website jurusan dalam memberikan informasi, fasilitas LCD dan fasilitas tempat ibadah. Oleh karena itu, disarankan kepada pihak jurusan perlu adanya evaluasi serta perbaikan agar mampu meningkatkan mutu pendidikan supaya dapat memberikan kualitas pelayanan sebaik mungkin sehingga dapa memenuhi atau sesuai dengan keinginan mahasiswa.

\section{DAFTAR PUSTAKA}

Adam, M. (2015). Manajemen Pemasaran Jasa. Bandung: Alfa Beta.

Aini, E. P., Masykur, R., \& Komarudin, K. (2018). Handout Matematika berbantuan Etnomatematika Berbasis Budaya Lokal. Desimal: Jurnal Matematika, 1(1), 73-79. 
DOI: https://doi.org/10.24127/ajpm.v8i1.1891

https://doi.org/10.24042/djm.vli 1.1950

Andriani, S. (2015). Evaluasi CSEUCLA Pada Studi Proses Pembelajaran Matematika. AlJabar: Jurnal Pendidikan Matematika, 6(2), 167-176. https://doi.org/10.24042/ajpm.v6 i2. 46

Anggoro, B. S. (2016). Meningkatkan Kemampuan Generalisasi Matematis Melalui Discovery Learning dan Model Pembelajaran Peer Led Guided Inquiry. Al-Jabar: Jurnal Pendidikan Matematika, 7(1), 11-20.

https://doi.org/10.24042/ajpm.v7 i1.23

Anggraeni, L. D., Deoranto, P., \& Ikasari, D. M. (2015). Analisis Persepsi Konsumen Menggunakan Metode Importance Performance Analysis Dan Customer Satisfaction Index. Industria: Jurnal Teknologi dan Manajemen Agroindustri, 4(2), 74-81.

Diana, N. (2017). Evaluasi Manajemen Mutu Internal di Fakultas Tarbiyah dan Keguruan dengan Metode Malcolm Baldrige Criteria for Education. Tadris: Jurnal Keguruan Dan Ilmu Tarbiyah, 2(2), 111-120.

Hartono, H. (2017). Mutu Layanan Dari Bagian Layanan Akademik Terhadap Kepuasan Dosen Di Universitas XYZ. Jurnal Riset Manajemen dan Bisnis (JRMB) Fakultas Ekonomi UNIAT, 2(1), 13-24.

Hidayati, A., Fudholi, A., \& Sumarni, S. (2014). Analisis Kepuasan Mahasiswa Terhadap Kualitas Pelayanan Tenaga Administratif Di Fakultas Farmasi Universitas
Ahmad Dahlan Yogyakarta. Pharmaciana, 4(1), 59-64.

Kotler, P., \& Keller, K. L. (2009). Manajemen Pemasaran (13 ed., Vol. 1-1). Jakarta: Erlangga.

Mahyudi, M. (2015). Penentuan TitikTitik Batas Optimum Strata Pada Penarikan Contoh Acak Berlapis Dengan Pemrograman Dinamik (Kasus : Pengeluaran per Kapita Propinsi Jawa Timur Tahun 2008). Al-Jabar: Jurnal Pendidikan Matematika, 6(1), 43-52.

https://doi.org/10.24042/ajpm.v6 i1.60

Marlina, L. (2016). Evaluasi Kualitas Pelayanan Proses Pembelajaran Di Prodi Manajemen Pendidikan Islam Fakultas Tarbiyah Dan Keguruan UIN Raden Fatah Palembang. El-Idare: Jurnal Manajemen Pendidikan Islam, 1(2), 145-157.

Suhendra, A., \& Prasetyanto, D. (2016). Kajian Tingkat Kepuasan Pengguna Trans Metro Bandung Koridor 2 Menggunakan Pendekatan ImportancePerformance Analysis. REKA RACANA, 2(2), 1-12.

Tjiptono, F. (2014). Pemasaran Jasa. Yogyakarta: Andi.

Tjiptono, F., \& Chandra, G. (2011). Service, Quality, \& Satisfaction. Yogyakarta: Andi.

Windasuri, H., \& Susanti, H. (2017). Excellent Service. Jakarta: Gramedia. 